\title{
Recovery of a Misinserted Gastrostomy Tube during Replacement: Effectiveness of Gastropexy Using a 'Funada Style' Kit
}

\author{
Hitomi Sakai Masahiko Inamori Hiroshi lida Keiko Akimoto Hiroki Endo Yuichi Nozaki \\ Tomoyuki Akiyama Yasunari Sakamoto Koji Fujita Hirokazu Takahashi Masato Yoneda \\ Yasunobu Abe Kensuke Kubota Norio Ueno Akihiko Kusakabe Atsushi Nakajima
}

Gastroenterology Division, Yokohama City University School of Medicine, Yokohama, Japan

Dear Sir,

Percutaneous endoscopic gastrostomy (PEG) is a widely accepted method of providing long-term nutrition. However, as this procedure becomes more common for nutritional support, numerous complications have been described. We describe a case in which a gastrostomy tube was misinserted during tube replacement; endoscopic gastropexy successfully prevented peritonitis in this patient.

A 65-year-old man was admitted for replacement of a gastrostomy tube, which had been inserted after an operation for neck cancer. Following tube replacement, a gastrografin study was performed through the gastrostomy tube; this study revealed that the tube had been misinserted. We immediately fixed the gastric wall to the abdominal wall using the gastropexy technique (fig. 1). The patient showed no symptoms suggesting peritonitis.

Gastropexy involves a technique in which the anterior gastric wall is non-surgically sutured to the abdominal wall. The procedure is often performed prior to the placement of a tube, and some studies have

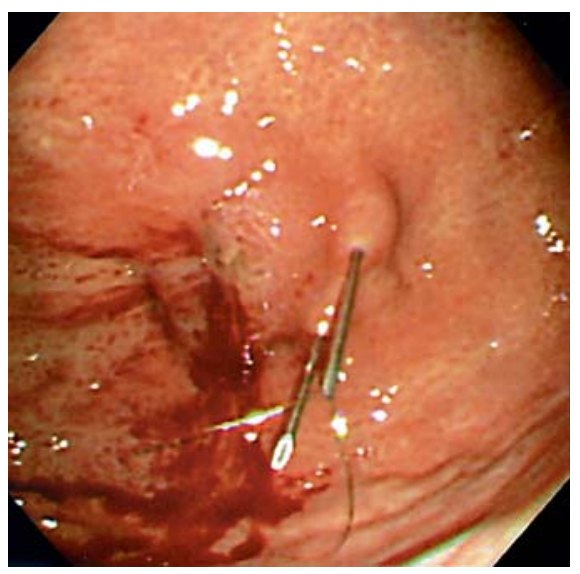

Fig. 1. Fixation of the gastric wall to the abdominal wall using a 'Funada-style' kit.

reported the efficacy of gastropexy using a 'Funada style' kit $[1,2]$. Our patient, with a misinserted gastrostomy tube, was successfully treated during replacement using the gastropexy technique.

\section{References}

1 Dormann AJ, Wejda B, Kahl S, Huchzermeyer H, Ebert MP, Malfertheiner P: Long-term results with a new introducer method with gastropexy for percutaneous endoscopic gastrostomy. Am J Gastroenterol 2006;101: 1229-1234

2 Kusaka K, Itoh T, Kawaura K, Yamakawa J, Takahashi T, Kanda T: Three-point fixation of stomach to abdominal wall in the percutaneous endoscopic gastrostomy procedure. Endoscopy 2005;37:494.

\section{KARGER \\ Fax +41 613061234 \\ E-Mail karger@karger.ch}

www.karger.com
(C) 2007 S. Karger AG, Basel

0012-2823/07/0754-0179\$23.50/0

Accessible online at:

www.karger.com/dig
Masahiko Inamori

Gastroenterology Division

Yokohama City University School of Medicine, 3-9 Fukuura, Kanazawa-ku

Yokohama 236-0004 (Japan)

Tel. +81 45787 2640, Fax +81 45784 3546, E-Mail inamorim@med.yokohama-cu.ac.jp 